\title{
Urokinase in the management of vitreous haemorrhage
}

\author{
J. S. CHAPMAN-SMITH AND G. W. CROCK
}

From the Department of Ophthalmology, Melbourne University, and the Ophthalmic Research Institute of Australia, at the Royal Victorian Eye and Ear Hospital, Melbourne

SUMMARY Urokinase is a plasminogen activator of human origin which breaks up the fibrin base of blood clots. When given as an intravitreal injection it produces hypopyon and glaucoma, both of which are transient. In a series of 27 patients (34 eyes) with unresolved vitreous haemorrhage, this simple and relatively atraumatic treatment has produced marked objective improvement in 10, and greatly improved the life styles of a further 9 . This series brings the total of reported cases to 93 . When compared with recent American reports of surgical vitrectomy for vitreous haemorrhage, intravitreal urokinase appears to have a higher success rate, with a lower complication rate both in the short and long term. This study suggests that, despite the high cost of the purified enzyme, urokinase should become the first line of attack in vitreous haemorrhage, vitrectomy being reserved for those patients who fail to respond.

Urokinase is a naturally occurring enzyme which was first isolated in urine by Ploug and Kjeldgaard (1957). They demonstrated its ability to dissolve blood clot. As interest grew in its potential clinical value, reports emerged suggesting that urokinase was helpful in the management of pulmonary embolism (Tow et al., 1967) and, in the dissolving of hyphaema (Pierse and LeGrice, 1963, 1964; Rakusin, 1971). A number of ophthalmologists have examined its role in the treatment of vitreous haemorrhage. Williamson and Forrester (1972) first reported the favourable effect of urokinase in the eye of a diabetic man. Vitreous haemorrhage had blinded the eye for more than 4 years before treatment. An injection of only 5000 Ploug units of urokinase in $1.5 \mathrm{ml}$ distilled water ultimately restored vision from perception of light to $6 / 12$ (Williamson and Forrester, 1973a, b). Their series has grown to involve 22 patients, 18 of whom benefited from urokinase (Forrester and Williamson, 1974; Williamson and Forrester, 1976). Dugmore and Raichand (1973) described 3 patients all of whom improved after the injection of 25000 Ploug units of urokinase into their vitreous. Less favourable results were obtained by Cleary et al. (1974), and Holmes Sellors et al. (1974), who between them treated 33 patients. Four of these had some improvement in visual acuity, 11 no change, and 2 a deterioration after treatment.

Address for reprints: Professor G. W. Crock, 32 Gisborne Street, East Melbourne, Victoria, 3002, Australia
An American study found that urokinase was ineffective in clearing experimentally induced vitreous haemorrhage in 4 speciosa monkeys (Koziol et al., 1975). These authors also observed that urokinase injected into monkey vitreous in doses of 22500 CTA units (15 750 Ploug units) or less produced no toxic effects on the eyes; 33750 CTA units (23 625 Ploug units) produced a localised whitish reaction on the monkey's retinal surface, considered to be a toxic effect. Other fibrinolytic agents used to treat experimental vitreous haemorrhages in rabbits have produced inflammation and necrosis and are known to be antigenic to man (Boyer et al., 1958; Maberley and Chisholm, 1970; Schimek and Steffensen, 1955).

Intravitreal urokinase has been used as the primary treatment of unresolved vitreous haemorrhage in the Melbourne University Department of Ophthalmology since May 1973. This study considers the outcome of intravitreal urokinase in 27 patients. A total of 34 eyes have been treated with urokinase. Three case histories are outlined, and the post-mortem findings in the eyes of a patient who died 6 days after intravitreal urokinase therapy are described.

\section{Methods}

The majority of patients were treated under local anaesthesia and light sedation in a procedure lasting only a few minutes. Preoperatively most patients were given $500 \mathrm{mg}$ acetazolamide, and the pupil of 
the eye in question was dilated with mydriatics. Sub-rectus stay sutures, under two appropriate rectus muscles, were used to expose either the lower or the upper temporal quadrants of the globe. The pars plana was approached through a scleral incision made parallel to the limbus and guarded by a mattress suture. Urokinase, freshly dissolved in $0.3 \mathrm{ml}$ distilled water, was introduced through a 30-gauge needle under indirect ophthalmoscopic control. Immediately before injection the anterior chamber was entered with a Saunder's needle and a small volume of aqueous released. Usually neither the ora serrata nor the posterior pole was clearly seen. Where practicable the posterior pole was studied for signs of vascular embarrassment. Frequently the eyes became stone hard after as little as $0.3 \mathrm{ml}$ of liquid had been introduced into the vitreous cavity. The mattress suture was tightened before removal of the needle. If the eye continued to feel hard, or showed signs of vascular embarrassment, further aqueous was released from the anterior chamber. Postoperatively topical antibiotic and mydriatic drops were frequently applied. Systemic antibiotic therapy was not given.

\section{Results}

Melbourne data to December 1976 are presented in Tables 1 to 5 . The patients' ages ranged from 25

Table 1 Melbourne data May 1973 to December 1976

\begin{tabular}{ll}
\hline Number of patients & $27-14$ male: 13 female \\
Number of eyes treated & 34 \\
Age range & 25 to 79 years \\
Duration of 'blindness' & 4 months to 13 years \\
Period of follow-up & 3 weeks to 36 months \\
Preoperative acuity range & Doubtful P of L-6/18 part \\
Dose range (Ploug units) & 5000 to 55000 \\
Commonest dosage & 25000 \\
\hline
\end{tabular}

\section{Table 2 Diagnoses}

\begin{tabular}{lc}
\hline Diabetes & 15 \\
Central vein occlusion & 2 \\
Hypertension & 3 \\
Over-anticoagulation & 2 \\
Eales's Disease & 3 \\
Trauma & 2 \\
\hline Total & 27 \\
\hline
\end{tabular}

Table 3 Visual change following 34 intravitreal urokinase injections

\begin{tabular}{|c|c|c|}
\hline Visual change & Number of eyes & Subsequent surgery \\
\hline $\begin{array}{l}\text { Improved subjectively } \\
\text { and objectively } \\
\text { (more than } 2 \text { Snellen } \\
\text { lines) }\end{array}$ & $\begin{array}{l}10 \text { (6 diabetic } \\
2 \text { aphakics) }\end{array}$ & $\begin{array}{l}3 \text { required lens extraction, } \\
\text { and } 1 \text { of them vitrectomy }\end{array}$ \\
\hline $\begin{array}{l}\text { Subjectively only (less } \\
\text { than } 2 \text { Snellen lines) }\end{array}$ & 9 & then retrobulbar alcohol \\
\hline Unchanged & 10 & $\begin{array}{l}1 \text { vitrectomy with } \\
\text { lensectomy }\end{array}$ \\
\hline Worse & 3 & $\begin{array}{l}1 \text { phthisis bulbi after } \\
\text { vitrectomy }\end{array}$ \\
\hline Lost to follow-up & 2 & \\
\hline
\end{tabular}

Table 4 Subjective and objective improvement group

\begin{tabular}{|c|c|c|c|c|}
\hline $\begin{array}{l}\text { Case } \\
\text { number }\end{array}$ & $\begin{array}{l}\text { Visual change } \\
\text { From }\end{array}$ & e & $\begin{array}{l}\text { Preoperative } \\
\text { diagnosis }\end{array}$ & $\begin{array}{l}\text { Duration of } \\
\text { blindness }\end{array}$ \\
\hline 1 & HM & $6 / 9$ & Diabetes & 3 years \\
\hline 2 & $\mathrm{CF}$ at $1 / 3 \mathrm{~m}$ & $\mathrm{CF}$ at $2 \mathrm{~m}$ & Diabetes & 18 months \\
\hline 4 & $6 / 36$ & $6 / 9$ latest $6 / 12$ & $\begin{array}{l}\text { Diabetes } \\
\text { hypertension }\end{array}$ & 12 months \\
\hline 8 & $P$ of $L$ & $6 / 9$ & $\begin{array}{l}\text { Hypertensive } \\
\text { vein occlusion }\end{array}$ & 3 years \\
\hline 10 & $6 / 36$ & $6 / 9$ & Hypertension & 4 years \\
\hline 11 & HM & $6 / 60$ & Diabetes & 12 months \\
\hline 15 & $\mathrm{CF}$ at $1 \mathrm{~m}$ & $6 / 6-2$ & Blast injury & 12 months \\
\hline 16 & HM & $6 / 75$ and N8 & Diabetes & 7 years \\
\hline 17 & $6 / 24$ & $6 / 12$ & Vein occlusion & 8 months \\
\hline 26 & $\mathrm{CF}$ at $2 \mathrm{~m}$ & $6 / 36$ & Diabetes & 12 months \\
\hline
\end{tabular}

$\mathrm{HM}=$ hand movements. $\mathrm{CF}=$ counting fingers. $\mathrm{P}$ of $\mathrm{L}=$ perception of light

Table 5 Miscellaneous data

Deaths: 1 on sixth postoperative day, from postanaesthetic cardiac arrest; 3 from late cardiac or renal failure

Multiple courses of urokinase: 2 patients had each eye treated; 3 patients had two injections into the same eye; 1 patient had three injections into the same eye

'Worse' category: 2 patients in 'worse' category had inoperable traction retinal detachment not related to urokinase therapy

Hypopyon: 22 eyes developed hypopyon postoperatively

years to 79. Fourteen were male, 13 female. Duration of 'blindness' in the eyes before treatment extended from 4 months to 13 years. The preoperative acuities ranged from $6 / 18$ part to doubtful perception of light. The duration of follow-up has been 


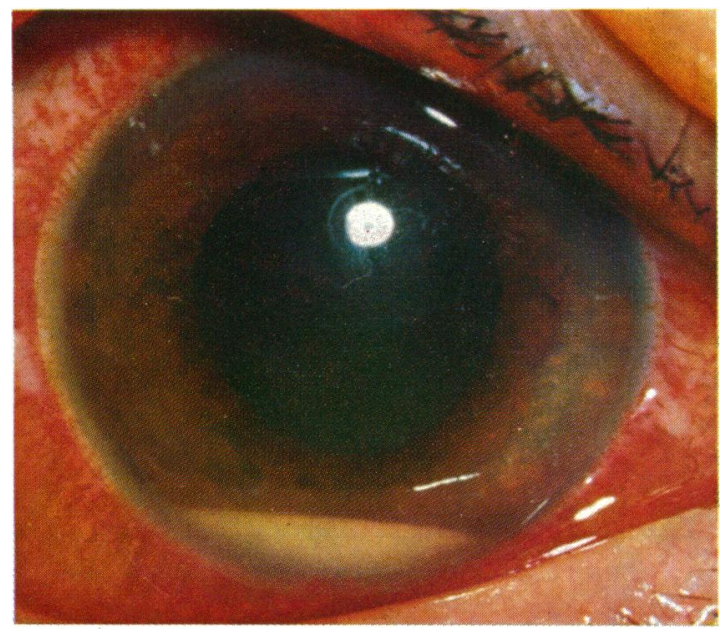

Fig. 1 The transient hypopyon which follows urokinase injection

from 5 weeks to 35 months. Four of the patients have died over the period of study.

Fifteen subjects were diabetic, 5 with high blood pressure. There were 3 cases of Eales's disease, 2 of central vein occlusion, 3 labelled hypertensive, 2 traumatic, and 2 having developed vitreous haemorrhages while on anticoagulants. The dosage of urokinase was most commonly 25000 Ploug units, given in $0.3 \mathrm{ml}$ distilled water.

Ten eyes improved objectively and subjectively, 6 of these patients being diabetic (Table 4). Subjective improvement only was noted in 9 eyes. In 10 the outcome was equivocal. In 3 there was deterioration, with associated dense cataract. Two were lost to follow-up.

There was a very high incidence of hypopyon in this series, 22 cases being encountered (Table 5). The usual hypopyon was white, flocculant, virtually painless, and not associated with any chemosis of the conjunctiva (Fig. 1). Folds in Descemet's membrane were a regular feature. In most cases hypopyon appeared within 48 hours of injection and resolved within 5 or 6 days regardless of topical steroid therapy. When subconjunctival dexamethasone $1 \mathrm{ml}$ was given at the time of operation, subsequent ocular inflammation seemed less. The data do not reveal whether hypopyon formation has any bearing on the final degree of vitreous clearing. The cellular nature of the hypopyon is not known.

Transient glaucoma, with pressures up to 36 $\mathrm{mmHg}$, were recorded in a number of cases, but no example of permanent intraocular pressure rise has been encountered. The effect on intraocular pressure has not been studied systematically.
More than one course of urokinase was given in 5 cases -2 injections into the same eye in 2 cases; 3 injections into the same eye in 1 case; injections into both eyes in 2 cases. The injections were all made some months apart.

Three VISC operations were performed after unsuccessful intravitreal urokinase. Four cataract operations likewise followed urokinase. Two were associated with VISC surgery, 1 as a lensectomy, 1 as an independent and simultaneous intracapsular lens extraction through a corneoscleral incision. One case of cataract was associated with postoperative intumescence of the lens and glaucoma. This lens was removed by intracapsular extraction. The glaucoma has now subsided, and the patient is awaiting a second intravitreal injection of urokinase. The fourth case of cataract has a postoperative acuity of 6/12. Two patients in the series had had elective cataract extractions done in one or both eyes prior to intravitreal urokinase injection.

The following three case reports are spectacular for the way in which the patients' life styles were so promptly and beneficially altered after urokinase. A general summary of findings is given in Tables 3 and 4.

\section{CASE I}

A male aged 23 years of Maori extraction was working on a road construction project when he was involved in a gelignite explosion on 15 December 1972. He suffered penetrating injuries to both eyes. When first seen in Melbourne on 13 November 1973 he had no perception of light in the right eye, the loss dating from the time of the blast injury. The left vision was counting fingers at $3 \mathrm{ft}(1 \mathrm{~m})$. The left fundus was obscured by dense red haemorrhage. On 14 November 1973, 25000 Ploug units of urokinase in $0.3 \mathrm{ml}$ water was injected into the vitreous cavity. At final follow-up, on 24 October 1976, the corrected vision in this eye was $6 / 6-2$, with $a-1 \cdot 25$ dioptre cylinder, axis 175 degrees. Fine posterior subcapsular lens opacities were present in this eye. The patient has returned his blind pension and rejoined the work force.

\section{CASE 2}

A 69-year-old woman was a known diabetic for 41 years. She had light perception only in the left eye for 9 years, from 1967. By August 1974 her right vision was reduced to light perception, but it improved to hand movements after removal of a dense haemosiderotic cataract. In March 1975 a right intravitreal urokinase injection was given under local anaesthetic and anterior chamber paracentesis performed. Postoperatively a hypopyon was noted. After being blind for 7 years this patient is now able 
to see $6 / 75$ with +14.0 dioptre sphere, and with $a \times 7$ magnifier, to read N8 print. The central area of the vitreous body has cleared, showing very marked posterior polar fibrosis from proliferative changes round the disc. This patient's life style and personality have been happily transformed.

\section{CASE 3}

A salesman aged 30 known to be diabetic for 22 years had been blind for 3 years in the left eye when he presented with a right vitreous haemorrhage of 5 days' duration. His right vision was counting fingers at $1 \mathrm{~m}$, and the left vision was hand movements. He had married recently.

As a result of the right vitreous haemorrhage he was unable to work. He was severely depressed. The right fundus showed fresh vitreous haemorrhage over the posterior pole, associated with background retinopathy and proliferation at the disc. The left fundus was obscured by old, whitish-yellow material and gliosis, with a red reflex visible peripherally. In December 1975, 25000 Ploug units of urokinase in $0.3 \mathrm{ml}$ water was injected into the left vitreous under local anaesthetic. Subconjunctival dexamethasone was given at the end of the procedure. A mild uveitis was noted postoperatively, but no hypopyon. No glaucoma was recorded. By December 1976 the left acuity was 6/9. The left fundus showed new vessels at the posterior pole; most of the old haemorrhage had cleared. The patient is working effectively again as a book seller.

A diabetic male aged 64 died 6 days postoperatively after postanaesthetic cardiac arrest, having remained deeply comatosed. Dr Hugh Greer provided the following histological report: 'Compared with the controls, the urokinase eye shows red cell debris and macrophages in and on a retinal surface membrane, having the appearance in places of the internal limiting membrane of the retina.'

These findings are the only histological changes reported in human material to this date. They would suggest that in the dosage of 25000 Ploug units human urokinase is not toxic to man's retina (Fig. 2).

The most serious post-urokinase complication appeared to be cataract, which is in any event amenable to surgery. No prolonged glaucoma or serious corneal disorder was encountered. This lack of corneal problems is particularly noteworthy where urokinase was administered to aphakic eyes. No eyes were lost.

\section{Discussion}

The fibrinolytic activity of normal urine was recognised by MacFarlane and Pilling (1947), and this was subsequently related to its property of activating

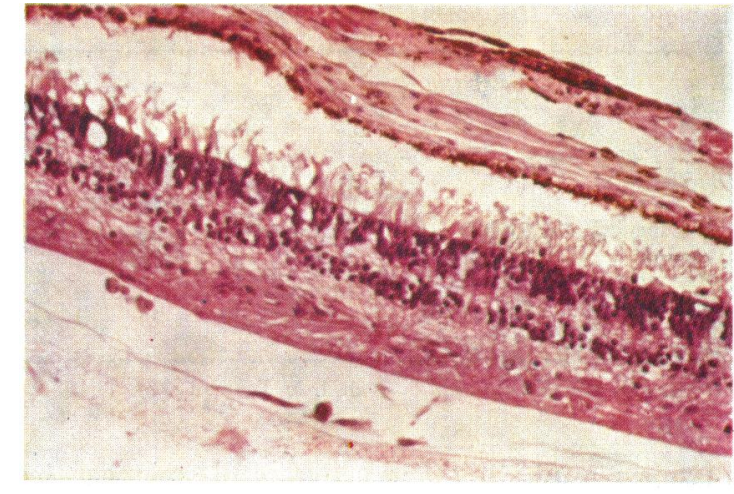

a

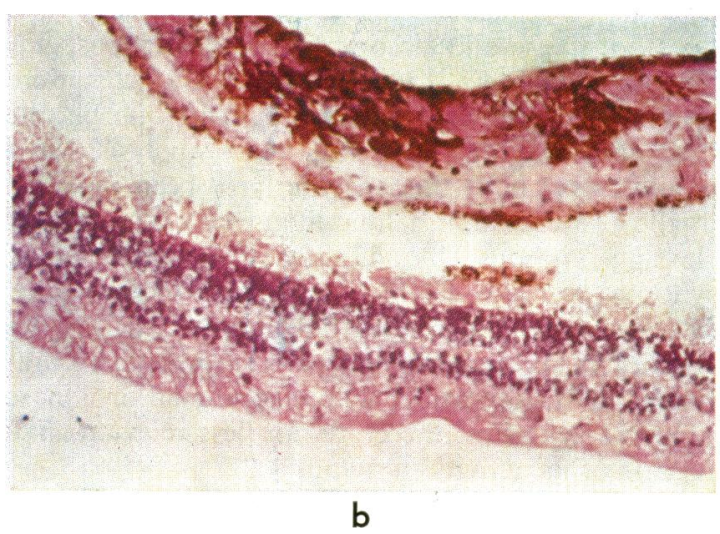

Fig. 2 Sections of retina from a 65-year-old male diabetic following urokinase injection $(H$ and $E . \times 380)$ :

(a) Urokinase eye (see text)

(b) Control eye

fibrinolysin (Williams, 1951). These findings were confirmed and extended by the results published by Astrup and Sterndorff (1952). A complete (direct) activator of plasminogen named urokinase was found to be present in urine. The observation that urokinase accumulated in the urine foam in concentrations approximately 100 -fold in potency over that in urine enabled Celander and co-workers to prepare urokinase in large quantities (Celander et al., 1955). Urokinase is a colourless, water-soluble protein which, when pure, is fairly stable within a large $\mathrm{pH}$ and temperature range (Ploug and Kjeldgaard, 1957). It has a molecular weight of 53000 and, as a proteolytic enzyme, induces lysis of fibrin by activating the transformation of the precursor, plasminogen (profibrinolysin) into active plasmin (fibrinolysin). Plasminogen-free fibrin is not attacked by urokinase, except in unusually high concentrations. It has greater preferential affinity for gel phase plasminogen within a thrombus than for soluble 
Table 6 Analysis of American vitrectomy experience 1976

\begin{tabular}{|c|c|c|c|c|c|c|c|}
\hline \multirow{2}{*}{ Patients } & \multicolumn{3}{|c|}{ Change in visual acuity } & \multirow{2}{*}{ Lens removed } & \multirow{2}{*}{$\begin{array}{l}\text { Retinal tear or } \\
\text { detachment }\end{array}$} & \multirow{2}{*}{$\begin{array}{l}\text { Persisting } \\
\text { glaucoma }\end{array}$} & \multirow{2}{*}{$\begin{array}{l}\text { Enucleation } \\
\text { phthisis, hypotony } \\
\text { lost vision }\end{array}$} \\
\hline & Better & Same & Worse & & & & \\
\hline 100 diabetics* & 30 & 66 & 4 & 84 & 16 & 11 & 20 \\
\hline 52 diabetics $\dagger$ & 8 & 40 & 4 & 39 & 0 & 7 & 1 \\
\hline 48 others $\dagger$ & 6 & 36 & 6 & 12 & 3 & 1 & 2 \\
\hline Totals 200 & 44 & 142 & 14 & 135 & 19 & 19 & 23 \\
\hline
\end{tabular}

•Date from Mandelcorn et al. †Data from Peyman et al.

plasma plasminogen, and activates plasminogen by first-order kinetics, probably by splitting lysine and/ or arginine bonds (Kjeldgaard and Ploug, 1957). It does not cause allergic or pyrogenic reactions, nor does it stimulate antibody formation. If cost were unimportant, urokinase would at present be the drug of choice for intravascular thrombolysis. Most of the facts about this enzyme have been included in the previous ophthalmic literature on its use for clearing vitreous blood clots. However, these synopses of the fibrinolytic system have failed to emphasise the repeatedly established species differences in the behaviour of that system (Konttinen, 1968). Reports of failure of human urokinase in animal vitreous, therefore, are less relevant than reports of its activity in man.

At present conflict exists between mechanical and biochemical approaches to the problem of vitreous haemorrhage. The Melbourne Department of Ophthalmology, whose contribution to VISC surgery is recognised (Machemer, 1976) has adopted urokinase as its primary method of treatment for unresolved vitreous haemorrhage. The findings of this study may be contrasted briefly with the reports of Mandelcorn et al. (1976) and Peyman et al. (1976) following vitrectomy. Their visual acuity findings were graded in 'acuity groups'. The standard criterion for significant acuity change, a two-line difference on the Snellen chart, was not followed. When their data are reanalysed by means of this criterion (Table 6) a comparison with the data of the urokinase study is of greater significance. The objective improvement following urokinase administration in the Melbourne series, shown in Tables 3 and 4, was based on this same two-line difference in the Snellen chart, except for cases 2 and 16 (Table 4).

The 44 cases of vitrectomy classed as improved under this scheme of reanalysis are impressive enough. However, the residue of misery in the failure group, the additional surgery, the glaucoma and corneal problems, not to mention lost eyes, demand some supplementary or alternative treat- ment. Urokinase deserves an equally careful, prospective evaluation as does vitrectomy in the management of unresolving vitreous haemorrhage. The results of this study suggest that it should be used as a first line of attack in vitreous haemorrhage, vitrectomy being reserved for those patients who fail to respond. The latest work of Forrester et al. (1976) goes some way to account for the mode of action of intravitreal urokinase on vitreous haemorrhage. It still does not explain how haemorrhages of more than 6 months' duration are broken up and cleared.

We thank Dr J. D. Cairns and Dr J. Reich for the opportunity to follow up their patients; $\mathrm{Mr} \mathrm{J}$. Scrimgeour for photography; and Mrs Beverley Vaudrey for her typing.

\section{References}

Astrup, T., and Sterndorff, I. (cited by Konttinen, Y. P.) (1952). An activator of plasminogen in normal urine. Proceedings of the Society for Experimental Biology and Medicine, 81, 675.

Boyer, H. K. M., Surian, A. A., Hogan, M. J., and McEwan, W. K. (1958). Studies on simulated vitreous haemorrhages. II: The effects of lytic enzymes, surface-acting agents and urea. Archives of Ophthalmology, 59, 333-336.

Celander, D. R., Langlinais, R. P., and Guest, M. M. (cited by Konttinen, Y. P.) (1955). Application of foam technique to the partial purification of a urine activator of plasma profibrinolysin. Archives of Biochemistry and Biophysics, 55, 286.

Cleary, P. E., Davies, E. W. G., Shulling, J. S., and Hamilton, A. M. (1974). Intravitreal urokinase in the treatment of vitreous haemorrhage. Transactions of the Ophthalmological Societies of the United Kingdom, 94, 587-590.

Dugmore, W. M., and Raichand, M. (1973). Intravitreal urokinase in the treatment of vitreous haemorrhage. American Journal of Ophthalmology, 75, 779-781.

Forrester, J. V., Edgar, W., Prentice, C. R. M., Forbes, C. D., and Williamson, J. (1976). Intravitreal fibrinolysis in experimental vitreous haemorrhage. Experimental Eye Research, 22, 181-188.

Forrester, J. V., and Williamson, J. (1974). Lytic therapy in vitreous haemorrhage. Transactions of the Ophthalmological Societies of the United Kingdom, 94, 583-586.

Holmes Sellors, P. J., Kanski, J. J., and Watson, D. M. (1974). Intravitreal urokinase in the management of vitreous 
haemorrhage. Transactions of the Ophthalmological Societies of the United Kingdom, 94, 591-596.

Kjeldgaard, N. O., and Ploug, J. (1957). Urokinase: an activator of plasminogen from human urine. II : Mechanism of plasminogen activation. Biochemia et Biophysica Acta, 24, 283-289.

Konttinen, Y. P. (1968). Fibrinolysis: Chemistry, physiology, pathology and clinics, p. 643. Star: Tampere.

Koziol, J., Peyman, G. A., Sanders, D. R., Vichek, J., and Goldberg, M. F. (1975). Urokinase in experimental vitreous haemorrhage. Ophthalmic Surgery, 6, 79-82.

Maberley, A. L., and Chisholm, L. D. J. (1970). The effect of fibrinolytic agent on vitreous haemorrhage in rabbits. Canadian Journal of Ophthalmology, 5, 59-63.

MacFarlane, R. G., and Pilling, J. (cited by Konttinen, Y. P.) (1947). Fibrinolytic activity of normal urine. Nature, 159, 779.

Machemer, R. (1976). Pars plana vitrectomy. Transactions of the American Academy of Ophthalmology and Otolaryngology, 81, 350-351.

Mandelcorn, M. S., Blankenship, G., and Machemer, R. (1976). Pars plana vitrectomy for the management of severe diabetic retinopathy. American Journal of Ophthalmology, 81, 561-570.

Peyman, G. A., Huamonte, F. U., and Goldberg, M. F. (1976). One hundred consecutive pars plana vitrectomies using the Vitrophage. American Journal of Ophthalmology, 81, 263-271.

Pierse, D., and Legrice, H. (1963). Urokinase in ophthalmology. Lancet, 2, 1143-1144.
Pierse, D., and Legrice, H. (1964). The use of urokinase in the anterior chamber of the eye. Journal of Clinical Pathology, 17, 362.

Ploug, J., and Kjeldgaard, N. O. (1957). Urokinase: an activator of plasminogen from human urine. I: Isolation and properties. Biochemica et Biophysica Acta, 24, 278283.

Rakusin, W. (1971). Urokinase in the management of traumatic hyphaema. British Journal of Ophthalmology, 55, 826-832.

Schimek, R. A., and Steffensen, E. H. (1955). Vitreous haemorrhage absorption. Experimental study on rabbit eyes of the effects of intravitreal hyaluronidase and streptokinase-streptodornase and on the influence of ACTH and cortisone. American Journal of Ophthalmology, 39, 677-683.

Tow, D. E., Wagner, H. N., Jr., and Holmes, R. A. (1967). Urokinase in pulmonary embolism. New England Journal of Medicine, 277, 1161-1167.

Williams, J. R. B. (cited by Konttinen, Y. P.) (1951). The fibrinolytic activity of urine. British Journal of Experimental Pathology, 32, 530.

Williamson, J., and Forrester, J. V. (1972). Urokinase in the treatment of vitreous haemorrhage. Lancet, 2, 488.

Williamson, J., and Forrester, J. V. (1973a). Treatment of vitreous haemorrhage with urokinase. Lancet, 1, 888.

Williamson, J., and Forrester, J. V. (1973b). Resolution of intravitreal clots by urokinase. Lancet, 2, 179.

Williamson, J. (1976). Personal communication. 